\title{
Science Fictioning Singularities: The Diagrammatic Imaginaries of Physics
}

\section{David Burrows}

* London, UK | London, UK

David Burrows is a London-based artist and writer teaching at Slade School of Fine Art, University College London, with an individual art practice, and as part of the UK-based collaboration Plastique Fantastique with Simon O'Sullivan, Alex Marzeta, Vanessa Page and others since 2005. Plastique Fantastique have exhibited and performed widely throughout the UK and internationally, and recently in: Tech-Animal Rendezvous at Reactors Halls, Primary, Nottingham (2020); Zero Time GiG Munich (2019-20); Mars Year Zero Southwark Park Galleries London (2019); Today Is Our Tomorrow, Publics, Helsinki; Horniman X at Horniman Museum London (2019); Shonky: The Aesthetics of Awkwardness, the Hayward Touring exhibition, mac Belfast (2017), DCA Dundee (2017-18) and Bury Art Museum and Sculpture (2018); They Call us the Screamers TULCA Festival of Visual Arts Galway (2017). Burrows is the co-author of the book Fictioning with Simon O'Sullivan (Edinburgh University Press, 2019), and a member of the interdisciplinary group Social Morphologies Research Unit (SMRU) made up of artists and anthropologists. Other past collaborations include the Diagram Research Use Generation Group (DRUGG) which produced the exhibition Plague of Diagrams, ICA London (2015) and working as part of the artist's group BANK. Burrows individual art practice has been exhibited at: ICA London, Fruitmarket Gallery Edinburgh, Bluecoat Liverpool (2001); Fredericke Taylor Gallery, New York (2002); Artspace Sydney (with DJ Simpson) (2003); Chisenhale Gallery London (solo show touring to Collective Gallery Edinburgh, Mead Gallery Warwick, Aspex Gallery Portsmouth) (2004); Chung King Project Los Angeles and Galerie Praz-Delavallade Paris (2006); Zabludowicz Collection (2010); Summerhall Edinburgh (2014); Eastside Projects Birmingham (2015); IMT London (2017); Helsinki Contemporary, Helsinki (2018); Horse Hospital, London (2019). Burrows received a Paul Hamlyn Award for Visual Artists in 2002 and an Arts Council England International Residency Award in 2003. Burrows and Plastique Fantastique are represented by IMT Gallery, London. 
Diagrams are in a degree the accomplices of poetic metaphor [...] Like metaphor they leap out to create spaces and reduce gaps [...] Unlike the metaphor the diagram cannot be exhausted.

\section{(François Châtelet)'}

\section{Fictioning singularities through diagrammatic imaginaries}

Science fiction commonly presents physical and social worlds shaped from science fact, often integrating fantastic natures and cultures to conjure alternative realities; a fictioning of the potential transformations of everyday and future life, or of the seemingly impossible, presented through the exploration of scientific ideas and technologies. Why is this a fictioning rather than a fiction? The latter term, a noun, names something generally thought to be made up-the anthesis of reality. The former term, a verb, refers to a practice which subverts, intervenes in or transforms a given or existing account of reality through fictional presentations. More than this, the concept of fictioning challenges the idea that fiction and reality are opposed to each other. While not asserting they are the same thing, this concept approaches fiction as an agent that changes, instantiates or produces worlds. ${ }^{2}$ By tracking this agent in scientific presentations, models and diagrams, this chapter argues that scientists can be seen to engage in science fictioning in ways similar to writers and artists. A question may arise here, what exactly is meant by the term reality? In attending to the sciences, and in particular astrophysics, this chapter certainly engages with various models of reality but without any attempt at assessing their veracity (sorry if this is disappointing). The focus remains throughout on the role fiction and the imaginary play in apprehending reality or understanding nature. This is not a new problem. Scholars point to Plato's anxiety concerning fiction and fictioning, present in diegetic and descriptive narratives, and a distrust of the imaginary can be found in many university and rule bound disciplines, precisely because the imaginary is not considered a reliable register. ${ }^{3}$ One contention of this chapter is that an imaginary register has often been called upon by the sciences to fiction worlds and realities. Indeed, while the sciences might be thought to counter the fictional, they can also be said to call upon the imaginary to refute human-centred or folk points of view. For example, neuroscientists, biologists and astrophysicists all present
1 François Châtelet (2000), Figuring Space: Philosophy. Mathematics and Physics, translated by R. Shore and $M$. Zahga, (Dordrecht: Kluwer Academic Publishers), 10.

2 A more detailed development of this point can be found in David Burrows and Simon O'Sullivan (2019), Fictioning: Myth Functions of Contemporary Art and Philosophy, (Edinburgh: Edinburgh University Press).
3 See in particular Jeffrey A. Bell (2006), Philosophy at the Edge of Chaos: Gilles Deleuze and the Philosophy of Difference, (Toronto: University of Toronto Press). Cf Max Statkiewicz (2009), Rhapsody in Philosophy: Dialogues with Plato in Contemporary Thought, (University Park PA: Pennsylvania State University Press), respectively. See also Burrows and O'Sullivan,

Fictioning, 2-3.

\section{belonging [bi'lnyı]}

the $a=a$ of parmenides, where identity has first to do with connection of the same to each other (belonging). heidegger exploits the $a=a$ move, emphasising the $=$ sign and not the end points ( $a$, a). without that = (the bridge linking and separating the 'a's), all 'a's would collapse onto the 'other' a. thus 'belonging' is both an attraction and, simultaneously, the need 'just to be' (alone). 
4 Albert Einstein (1972 [1917]), "The Fundamental Idea of General Relativity in Its Original Form," unpublished essay, documented as "Excerpt from an Essay by Einstein on 'Happiest Thought' in His Life," (New York: The New York Times) Tuesday, 28 March 1972.

5 Samuel Delany (1994), The Silent Interviews, (New England: Wesleyan University Press), 168. realities not apparent to the human senses, using images, models and narratives to do so. Here, we only have to think of Einstein's tale about gazing out of a window and observing the (imaginary) body of a human in free fall; an image that facilitates an insight concerning gravity and the reason why the unlucky human does not feel their own weight as they plunge to the ground. ${ }^{4}$

There is perhaps nothing special about this. As suggested above, fiction abounds in human presentations and discourses and, furthermore, an imaginary register allows humans to correlate images, symbols and words with an experience or an understanding of reality. It is the imaginary that conjures worlds that are not close to hand or that do not yet exist, and which registers a snap of a twig (an indexical sign) as an approaching predator, an evolutionary trait shared by humans and other animals. A difference can be marked here though. Humans, unlike many animals, have the capacity to imagine events across times and spaces, and pasts and futures. Furthermore, scientists may draw upon intuitive capacities but images of the big bang, black holes and the superposition of particles are, for the most part, not intuited in this sense, often having a third person perspective and being identifiable as diagrammatic in two ways. Firstly, when expressing mathematical or quantitative orders or hierarchies, the imaginary at work in the sciences is often diagrammatic, producing spatial compositions to differentiate and present relations and states, even when this involves marking processes, time or duration. Molecules, photosynthesis and cosmic inflation are all articulated through diagrammatic explanations-spatial presentations-in textbooks and popular science publications. Secondly, the imaginary of the sciences is diagrammatic in its effect on thought, in that it produces a rift-a structural division or disjunction-not just between perceived and invisible or existing and past or future worlds, but between intuitive and counter intuitive accounts of reality. It is this double aspect-of a division of a world in presentation and in thought-that points to how the sciences are generative of, but also engendered by, a diagrammatic imaginary. Scientific diagrams and images, in being machines that generate counter-intuitive presentations, have something of a correspondence with the 'paraspaces' of science fiction. Samuel Delany coined the term paraspaces to describe parallel zones (within fiction) in which the forms or laws of natural and social relationships differ radically. ${ }^{5}$ It is Delany's contention that in science fiction, the presentation of a 
paraspace produces a divergent reality which disrupts any hierarchies of reality and fiction within a narrative. The comparison made above does not find a symmetry between art and the sciences though: the sciences tend to develop counter-intuitive narratives and images from observation, data and calculations, which question folk ideas or existing models of reality; whereas art-following Delany-produces alternative worlds or spaces through presentations and reflections that invert, refract, abstract or contradict common accounts or experiences of reality. Where there is a convergence is in the way the imaginary register is mobilised to produce new, extra or multiple perspectives, and not just through images and assemblages, but performances and words too, as demonstrated by the writing of paraspaces in science fiction novels. This is not to say that the sciences produce myths, or invent alternative worlds in the same way science fiction does; it is only to suggest that the diagrammatic imaginaries of the sciences-just like the narratives and worldings of science fiction-present realities and events that contrast with or disrupt the world according to common sense or experience.

\section{Diagrams as islands of truth and hybrid devices}

\section{A diagram can be defined as a presentation of elements in a} composition. It is important to emphasise again, that diagrammatic presentations, first and foremost, are spatial in character-even when a given modelisation is a mental operation or concerned with temporality rather than spatial dimensions. In this, a diagram does not necessarily place elements together in actual, geographical or measured relation. Diagrams may share characteristics with maps or figurative representations, but they have different functions, as implied above, one significant function being that diagrams make visible and intelligible what is not apparent to the eye. For this reason, some presentations are more relevant than others to this discussion, particularly diagrams of actual and virtual relations, and events known as singularities (defined as unpredictable events which defy rulebased analysis). In this, objects known as black holes are of special interest.

Here, at the outset, it is important to stress that any knowledge articulated about black holes and other objects studied by astrophysics in this chapter is gleaned from material which scientists

\section{big data [big 'deita]}

has little to do with size, quality, or even quantity. underscores an unrelenting ability to rename, archive, and/or install all encounters, products, memories and communication economies into 'information', which in turn can be siphoned / individuated into silos of information economies, monetarised and re-calibrated to great political effect. 
6 Donna Haraway (2016), Staying with the Trouble: Making Kin in the Chthulucene, (Durham and London: Duke University Press), 11-12.

7 Michèle Le Dœuff (2002), The Siphoned Philosophical Imaginary, translated by C. Gordon, (London:

Continuum), 8-14.

8 Immanuel Kant (2003 [1787], The Critique of Pure Reason, translated by J. M. D. Meiklejohn, (London: J. M. Dent and Sons Ltd), 180.

9 Bruno Latour (1993), We Have Never Been Modern, translated by C. Porter, (Cambridge MA: Harvard University Press), 9. Never Been Modern, 30. produce to share, popularise and explain the general significance of their work, both to a lay-public and to each other. From the perspective of an art practitioner, when reviewing presentations of the sciences, it seems important to draw attention to the mediations of diagrammatic imaginaries. Just as it matters what stories tell stories and make worlds, as Donna Haraway (following Margaret Strathern) has stated, it matters what mediations present worlds. ${ }^{6}$ In Michèle Le Dœuff's The Philosophical Imaginary an argument is put forth that even the most abstract systems of thought can produce imaginary figures. ${ }^{7}$ To further this thesis, Le Doueff's points to Immanuel Kant's warning about the dangers of venturing beyond the horizon of what is known. Paradoxically, Kant issues this advice through the metaphor or image of an 'Island of Truth,' described as having firm ground and unalterable limits; a territory surrounded by the stormy waters of illusion-a diagrammatic and fictional image that draws a boundary line between the reliable firmness of land and the deceitfulness of water. Importantly, even Kant admits the 'Island of Truth' is a seductive phrase. ${ }^{8}$ Such a declaration though, as Le Doueff points out, may signal a distrust of seduction but, at the same time, the (imaginary) 'Island of Truth' continues its enchanting work. This leads Le Doueff to ask whether didactic images are merely vehicles for the realisation and dissemination of ideas-and should thus be paid little attention-or whether a use of images coupled with a denial of their importance is a negation of the role of the imaginary in critical or scientific thought. In raising this problem, Le Doueff asks whether (philosophical) fantasy figures can be separated from the emblems or functions of reason. Similarly, a question can be posed as to whether the imaginary figures of the sciences are more than vehicles for data and ideas, for they have social or aesthetic functions too. Are such devices best thought of as nature-culture assemblages? There is another French philosopher that is hard to ignore here, Bruno Latour, who argues in We Have Never Been Modern that the Enlightenment separation of the study of nature from the study of the human produces a "modern constitution" founded on the purification of objects of study. ${ }^{9}$ This is a poor state of affairs which produces a blind spot. Between these two disciplinary poles-which study either natural objects or societies and subjects-Latour asserts that a number of quasi-objects and quasi-subjects are found.10 
To find such "hybrids," Latour suggests that one only has to pay attention to the news, which provides many examples, including measurements of the ozone layer where chemical and political reactions mix, and (with a nod to Haraway's ironic, fictional figure) the development of cyborgs, which might be the quintessential subject/object."1 One could add to this list black holes and the big bang, which have prompted discussions concerning future energy sources and the idea that something came from nothing, which, apart from other things, challenges religious beliefs.
11 Latour, We Have Never Been Modern, 1.

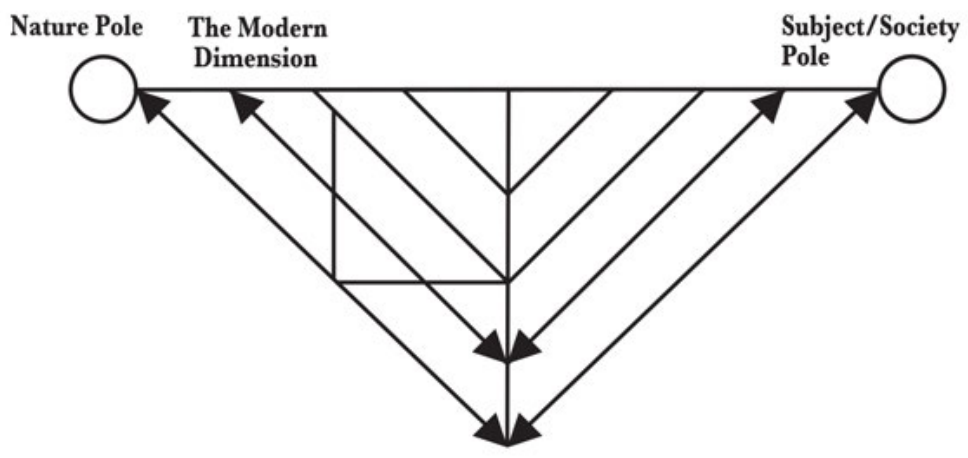

The Nonmodern

Dimension

Fig. 1: Diagram of purification and mediation by Bruno Latour, in We Have Never Been Modern, 1993, page 51. 
12 Latour, We Have Never Been Modern, 55.

13 Bruno Latour (1998), "How to be Iconophilic in Art, Science and Religion", in Carrie Jones and Peter Galison (Eds.), Picturing Science Producing Art, (London: Routledge), 418-40.

14 The painting in question is by Italian Renaissance master,

Fra Angelico is his Resurrection of Christ, c 1432-34. Latour, 'How to be Iconophilic', 421.
Latour's own diagrammatic imaginary can be seen at work in his diagram of purification and mediation (Fig. 1), a spatial arrangement that places nature registered through the sciences on one side of the figure (as the nature pole), and the study of the human at the other end (as the subject/society pole). In between the two poles there is, according to Latour, a dimension elided by modernism and Enlightenment discourse, which is the space in which hybrids of nature and society are produced (as non-modern mediations). What is interesting here is that, following Latour, it can be inferred that scientific diagrams are hybrid devices. They are social fabrications that can register what is "real, nonhuman and objective."12 Latour is critical of the sciences for not always understanding this-a view that is expressed, rather forcibly, in an essay by Latour titled How to be Iconphilic in Art, Science and Religion in which Latour offers a provocative example-a photograph of-a group of soil scientists huddled around a chart or map. ${ }^{13}$ In Latour's narrative, one scientist points to the centre and says, "Here it is." Latour, perhaps unjustly, compares this photograph with a painting by Fra Angelico in which an angel speaks to the followers of Jesus looking into the empty void of Christ's tomb and says, "Why do you look for the living amongst the dead," succinctly presenting Latour's own question: why look to images and mediations for signs of life? ${ }^{14}$ The moral is clear: images and other devices can be understood as pointing to, rather than capturing something.

However, Latour's critique of scientific representations, by way of Christ's ascension, only takes us so far. For Latour, images might mark the absence of a diagrammed or mapped thing, like the space for a body in an empty tomb or (as we shall see) a diagram of a black hole rendered through the drawing of a cone or circle, but there is more to images, to maps, figures and particularly diagrams, than representation. While it is important to heed Latour's point, the philosopher's discussion of iconophilia conveys a similar warning (or moral) to that offered by Kant-do not mistake images for reality, stay on firm ground, do not lose yourself in a sea of the imaginary. Without losing sight of the seductive power of mediation and the imaginary, there is an alternative line that can be taken to Latour's critique of representation: images such as maps and scientific diagrams and similar devices have both indexical and generative 
(or fictioning) functions, as Le Doueff implies. This is to say, the firm ground of what can be known (and that of indexicality) is entwinned with the imaginary-how else can we think of or conjure firm ground? Similarly, the imaginary articulates mediations of the unknown and unknowable, of events such as singularities and quantum gravity. It is to this function that we now turn.

\section{Beyond the horizon}

Why are black holes relevant to a discussion of diagrammatic imaginaries? It is because they are commonly registered and presented by scientists by marking a horizon and by drawing a curious figure-ground relation. Humans first encountered such singularities in mathematical calculation and in the mind rather than in space; that is, collapsing stars were encountered through thought experiments rather than perception. It is generally accepted that the first recorded 'appearance' of a collapsing star is in a letter written by John Michell in the 18th century, though it is not until the 20th century that such events were named 'black holes.' Michell, after studying the work of Newton, speculated on the existence of a heavenly body so dense that not even light could escape its influence-a proposal made a couple of centuries before the invention of instruments able to identify the effects of black holes. Importantly, black holes are points where mathematics and physics falter and space-time collapses. As such, the presentation of a collapsing star, in space and time (on a screen, page of a book or in the mind), is paradoxical: it is a presentation of something not present or which withdraws from presentation.

Most accounts of collapsing stars in popular science books offer similar narratives about the fate of matter, astronauts, spaceships, televisions and other domestic objects as they are trapped or swallowed by black holes. From reading such tales, many will know that a rotating singularity is thought to be circled by an accretion disc-matter positioned far enough from the collapsed star to escape being dragged to its centre but not far enough away to escape its influence, producing the horizon of the singularity, or the event horizon, beyond which nothing escapes. At the centre of the singularity, the laws of physics are replaced by quantum gravity, which, as experts tell us, is not (yet) understood. The name black hole seems appropriate though-as astrophysicist Kip Thorne explains: 
15 Kip Thorne (2012), Interview at space. com/17086-bizarre-black-holeskip-thorne-interview.html

16 The first use of the term black hole in print was by Ann Ewing (1964), "Black Holes in Space," Science News, vol. 85, 39. Ewing did not credit anyone with originating the term but reported that she had heard the phrase at a meeting of the American Association for the Advancement of Science. Wheeler introduced the term, years later, in his lectures of 1967.

17 C. W. Misner, K. S. Thorne and J. A. Wheeler, Gravitation, San Francisco: W.H. Freeman, 1973, 875-6.

18

J.M. Bardeen, B. Carter and S. W. Hawking (1973), "The Four Laws of Black Hole Mechanics," in Communications in Mathematical Physics, (Heidelberg: Springer), no 31, 161-70, and Stephen Hawking, M.J. Perry and A. Strominger (2016), "Soft Hair on Black Holes," available at: arXiv.org.
"[T]he atoms of which a star is made, are destroyed at the centre of a black hole [...]. The matter is gone, but the mass, in the sense of mass and energy being equivalent, has gone into the warped space-time of the black hole."15

The name 'black hole' diagrams an effect seen by an observer looking at a singularity. Until recently, photographing this effect was thought impossible, but in 2019 the Event Horizon Telescope captured an image of the silhouette of a collapsing star by recording the image of hot gas falling into a singularity (Fig. 2).

Impressive as this photograph is, an image of a singularity-as if seen by an observer-was realised long before a lens was able to do so, through diagrams delivering more than a photograph can offer (at present). It is not just that a diagrammatic imaginary adds visual detail to mathematical calculation, it is that black hole diagrams have allowed humans to view the horizon and warped space of a collapsing star, as if from an (as yet) impossible location in space (Fig. 3 and 4).

\section{R U diagrammed}

Few astrophysicists have reflected on the diagramming of horizons, singularities and the quantum with more invention than John Wheeler, who is credited with coining the term 'black hole' in 1967.16 Wheeler asserted that any matter or information crossing the event horizon of a black hole is lost forever. He famously stated that black holes do not have 'hair', that is, no traces or details are left of the morsels swallowed by black holes save the mass, charge and angle of the collapsing star's rotation. ${ }^{17}$ Since the 1970s, however, Wheeler's theories have been questioned and astrophysicists have accepted that black holes may be white hot, leak radiation and may even evaporate (which would thus return information to the universe). More recently, the late Stephen Hawking, famous for Hawking's law of area increase in accordance with Wheeler's theories, has challenged Wheeler's image of a black hole, proposing that singularities have fluctuating (apparent) horizons which ebb and flow and change like the weather; that is, they have 'soft hair' and return information to the universe. ${ }^{18}$ What is of concern here though is the art rather than the accuracy of Wheeler's diagrammatic imaginary. Wheeler, in Beyond the Black Hole, comments on the art of interrogating horizons (in landscapes and in physics) by drawing an analogy between Einstein

\section{blood poetics [blıd pəo'ztıks]}

an inhabited, raw, erotic and sometimes dirty form of logic. an ana-concept invented by johnny golding to indicate the importance practice-led reality which rifts off the sensations of rhythm, beat, pattern. entangled with the refusal to look away. linked to radical empathy, and the courage to know (the whatever). 
Fig. 2: Silhouette of a black hole captured by The Event Horizon telescope, in Jet Propulsion Laboratory, California Institute of Technology, at jpl.nasa.gov/ edu/news/2019/4/19/how-scientists-captured-the-first-image-of-a-black-hole/

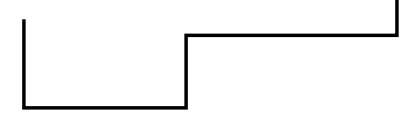

Fig. 3: Diagram of a black hole, illustration by ESO, ESA/Hubble, M.Kornmesser/N. Bartmann and Labels by NASA/CXC, reproduced in Chandra X-Ray Observatory at chandra.harvard.edu/blog/node/737
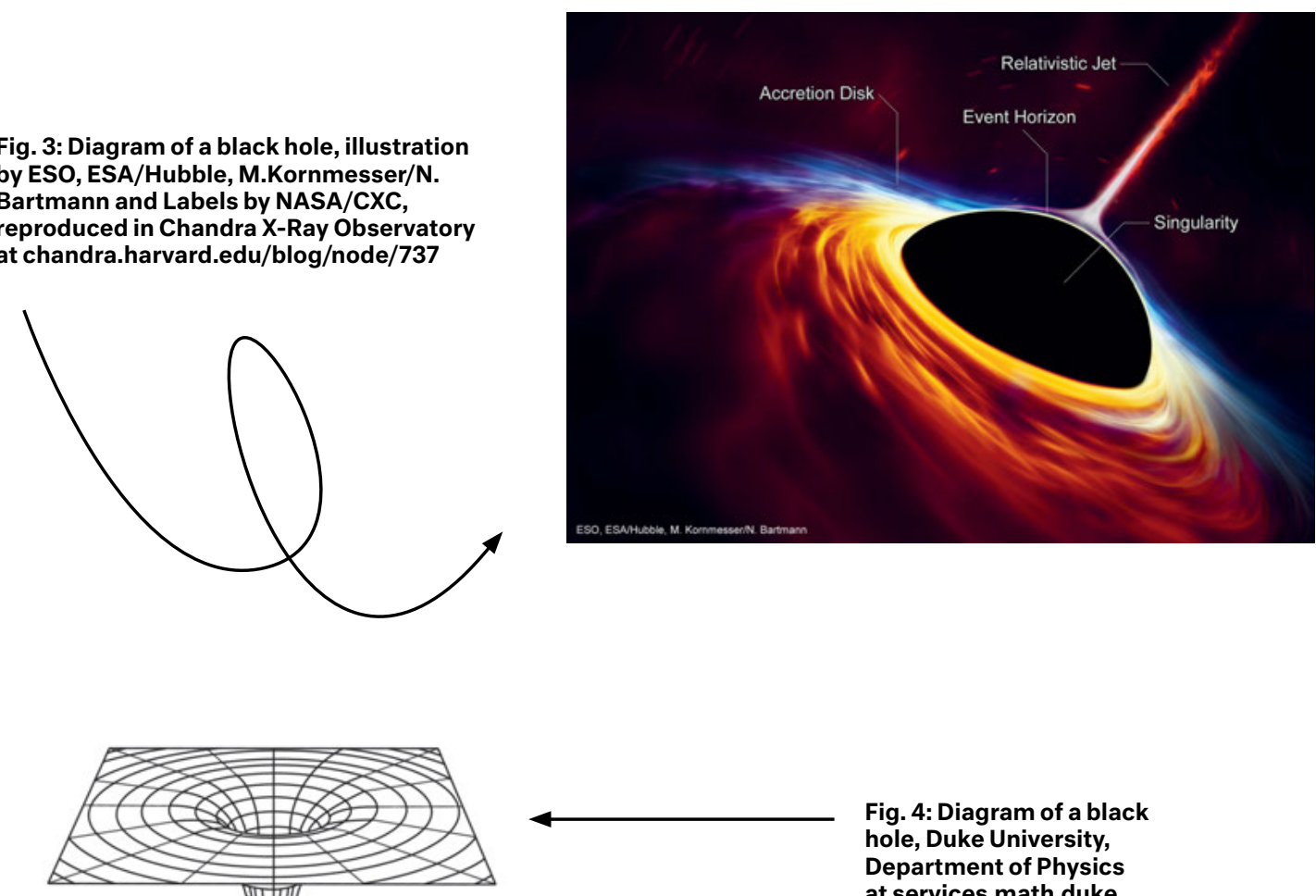

Fig. 4: Diagram of a black hole, Duke University, Department of Physics at services.math.duke. edu/ psa/cls/527/v 
19 John Wheeler (1978), "Beyond the Black Hole," in H. Woolf (Ed.), Some Strangeness in Proportion: A Centennial Symposium to Celebrate the Achievements of Albert Einstein, (Reading, MA: Addison-Wesley Publishing Co), 341-75.

20 Beyond the Hole, 341.

21 John Wheeler, Beyond the Black Hole, 358.

22 John Wheeler, Beyond the Black Hole, 362. and the Duke of Wellington: the latter could guess well enough the lay of the land beyond a hill by observing the surrounding landscape. ${ }^{19}$ For Wellington, like Einstein, the increasing strangeness of a territory indicated that a new terrain lay ahead. Wheeler follows this discussion of how to fathom what lies beyond a horizon with two paradoxes for physics. The first is that black holes, in being the most accessible example of the bounds (or limits) of time, is where physics (as the eternal laws of matter, space and time) stops, but this terrain is also where physics continues (insofar as it theorises the quantum and the event of a singularity that defies laws). The second paradox is that in every elementary quantum process, the act of registration-the act of observation-participation-plays an essential part in giving 'tangible reality' to what the observer says is happening. As Wheeler writes:

"The universe exists 'out there' independent of acts of registration, but the universe does not exist out there independent of acts of registration."20

Many questions follow, not least, one already mentioned: what, then, is reality? John Wheeler's answer is a drawing (Fig. 5), which he explains by writing: “What we call 'reality,' is symbolized by the letter R in the diagram, which consists of an elaborate papier-mâché construction of imagination and theory filled in between a few iron posts of observation." ${ }^{21}$

The astrophysicist views (what we call) reality as sculpted and, for the most part, "the construction of the imagination:" a science fictioning then, which supplements observations concerning reality. Wheeler extends this idea by presenting a second diagram, the letter $U$ with an eye perched on one of its arms (Fig. 6).

"The universe viewed as a self-excited circuit-starting small (thin $U$ at upper right), it grows (loop of $U$ ) and in time gives rise (upper left) to observer-participancy-which in turn imparts 'tangible' reality to even the earliest days of the universe."22 To complicate matters further, Wheeler raises one more problem by asserting that every law of physics, pushed to the extreme, will be found to be statistical (or a statistical probability) and approximate, and not mathematically perfect and precise. And it seems today, it is still not (yet) possible to pass beyond the horizon of the quantum: the uncertainty principle of quantum physics states that the position and momentum of a particle cannot both be calculated with accuracy. 


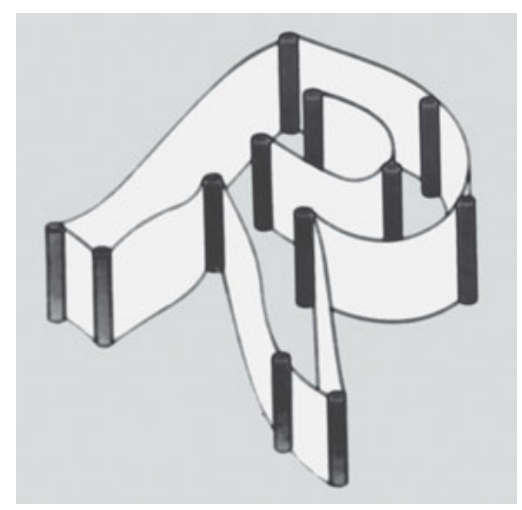

Fig. 5: 'What we call reality' by John Wheeler (1978), 'Beyond the Black Hole', in H. Woolf (Ed.), Some Strangeness in Proportion: A Centennial Symposium to Celebrate the achievements of Albert Einstein, (Reading, MA: Addison-Wesley Publishing Co), 358.

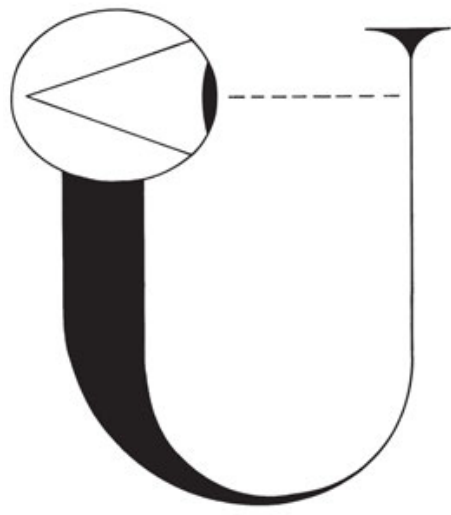

Fig. 6: 'The universe viewed as self-excited circuit' by John Wheeler, 'Beyond the Black Hole', in H. Woolf (ed), Some Strangeness in Proportion: A Centennial Symposium to Celebrate the achievements of Albert Einstein, Reading, MA:

Addison-Wesley Publishing Co, 1978, 362

blue [blu:]

code for liveness and sensuality of the semi-detached variety. underscores flow, light wave and thinking outside the box, as in 'blue sky' thinking. associated with a certain kind of certainty, melancholy, oceanic knowledge, flight lines. 
23 Robert Smithson (1969), Yucatan Mirror Displacement 1-9, Nine colour prints from slides each $61 \mathrm{~cm}$ $\times 61 \mathrm{~cm}$ at guggenheim-bilbao.eus/ en/learn/schools/ teachers-guides/ yucatan-mirror-displacements-1-9-1969
Once the location of a particle is defined its trajectory cannot be calculated, and vice versa. This is a different but related problem to that of the observer-participant effecting (or producing) reality through registration. It would seem uncertainty results from the quantum itself, which leads Wheeler to ask how to proceed with a law without law. This is a preposterous question, he writes, until he remembers the 'miracles' performed by Einstein who-through an imaginary articulation of mathematical calculation-is able to travel at the speed of light. It seems that for Wheeler, the answer to the problem of a 'law without law' is to embrace the diagrammatic imaginary of the observer-participant as an important aspect (or art) of science. In this, we find a scientific, disembodied third person perspective given embodiment (or given relation to embodied knowledge) through a marking of agencies, boundaries and limits.

\section{Diagrammatic tensions}

While artists may lack the necessary knowledge to interrogate singularities, they can offer insights concerning observation and participation, horizons, vanishing points and embodiment. And it is these insights that might help us further understand the diagrams of scientists such as John Wheeler. The example of Robert Smithson's mirror displacements is relevant here. In Yucatan Mirror Displacements 1-9 (1969), nine photographs record 12 mirrors cantilevered in soil or sand or wedged in trees. ${ }^{23}$ The photographs capture both the mirrors in situ and the mirror's reflections of an environment, including the surrounding ground from which artist and camera (and viewer) look at the arrangement of mirrors. But the photographs seem to have a blind spot, a vanishing point. The mirrors are carefully placed to produce a reflection-a visual field-in which camera and artist are absent; observer-participants are not captured or seen but registered all the same as invisible agents that produced the photographs. For understandable reasons, scientific diagrams-such as those of black holes-do not tend to reflect upon the position or viewpoint of the observer-participant or producer of a diagram. Firstly, this could produce an infinite regression of viewpoints and secondly, when nature is the subject why dwell on the performance and mediation of an observer-participant-this could be unproductive.

But in his Yucatan Displacements, Smithson manages to produce 
images of nature and also diagram the contingencies and agencies of media and observer-participant (although, paradoxically, they are not visible). He does so by attending to the displacements (and violence even) of overcoming or eliding human perspective, presence or scale. Smithson makes explicit what is implicit in Wheeler's diagrams by placing third and first, and disembodied and embodied viewpoints in tension. To expand upon this and add further definition to the terms diagram and diagrammatic imaginary, the chapter now turns to the work of Charles Sanders Peirce and François Châtelet, which can be said to produce two different and important diagrammatic orientations. Peirce is interested in how thought is mathematical, and he develops 'existential graphs' or diagrams to facilitate logical thinking and to express better the mathematical thinking of relations. ${ }^{24}$ It could be said that, in this, thought descends on or sees the world from above, or through a disembodied eye. Châtelet, on the other hand (and referencing Schelling) argues that thought can be "in the morning dew," which is an idea that underpins the philosopher's interest in diagrams that actualise or embody virtual potential and perspectives. ${ }^{25}$

\section{Logic cuts}

Peirce describes a diagrammatic arrangement as a specific kind of sign-as an icon of intelligible relations. ${ }^{26}$ To grasp this idea, it is important to understand that the philosopher's approach to diagrams relates to his reflections on how humans attend to the world. Peirce suggests that when something catches our attention (which he calls a "first thing" or "firstness") a second thing follows and we notice that other things exist too. In attending to something, such as a city, we become aware of other things (which he calls a "second thing" or "secondness"), such as roads that lead away from the city to other places. Peirce's mathematical thinking on attention does not end with the count of two. He argues that there is a third thing which comes to our notice in this process of attending to first and second things. This is not simply another, counted object or thing. Rather, this third thing (which Peirce names "thirdness") is an inference concerning the relation of firstness and secondness. ${ }^{27}$ Pierce pursues these relations through diagrammatic compositions he names existential graphs. Designed as an alternative to algebraic writing, the graphs have fixed
24 See Charles Sanders Peirce (1906), "Prolegamena for an Apology for Pragmatism," in The Monist,

(Oxford: Oxford Academic Press) at TheWealthofNation.com.

Peirce explains that in making his graphs he uses paper that has two differently textured sides, one smooth and the other with a tincture. A graph is produced by cutting out a shape that is reversed and placed back in the hole made by the cut.

25 Gilles Châtelet (2000), Figuring Space: Philosophy, Mathematics and Physics, translated by R. Shore and M. Zahga, (Dordrecht: Kluwer Academic Publishers), 4.

26 Charles S. Peirce (1991), Peirce on Signs, (Chapel Hill: North Carolina Press), 252.

27 Charles S. Peirce (1998), The Essential Peirce, (Bloomington: Indiana University Press), 240. 
functions and offer insight into how a diagrammatic imaginary is mediated or actualised. Peirce states that a diagram can be produced through using a blank sheet of paper to mark out assertions, the blank page standing in for the universe (or a continuum). By marking or isolating a part of this sheet, something-a first thing-is counted as existing in the universe, which is produced by cutting out a thing from the universe (a diagrammatic imaginary is in full effect here). Pierce offers practical instruction to make graphs: scissors can be used, or a pencil can be applied to draw an unbroken line, to produce an enclosed zone or figure, a first thing (Fig. 7).

Further to this, Peirce suggests a broken or dotted line can be drawn to render shapes within an enclosed figure and mark out the elements or attributes of a first thing (similar to the arrangements of elements in mathematical formula or sets). The relations of first and second figures are inscribed through annotations or marks (signs that Peirce calls "rhemes") which add information, such as the quality or distinctiveness (or function or specific relation) of diagrammed elements.

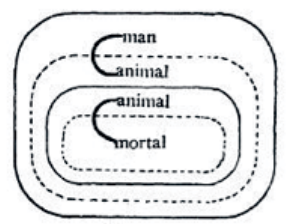

Fig. 17.

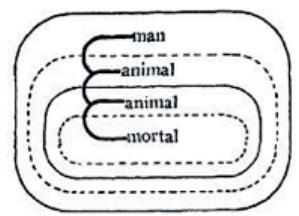

Fig. 19.

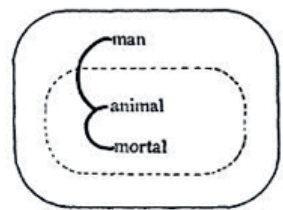

Fig. 21.

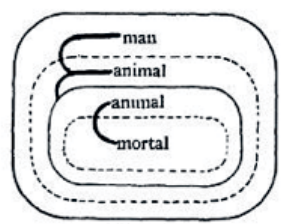

Fig. 18.

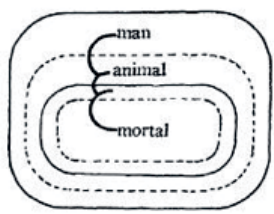

Fig. 20.

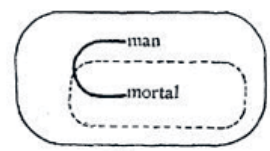

Fig. 22.

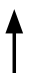

Fig. 7: Example of Existential Graphs by C. S. Peirce (1906), 'Prolegamena for an Apology for Pragmatism,' in The Monist, Oxford: Oxford Academic Press atTheWealthofNation.com 
These signs include "lines of identity" such as a branch, ligature or network connecting points, and what Peirce calls "selectives" in the form of numerals, words or capital letters, which represent or identify an isolated figure or what Peirce calls a "bound or cut individual variable." In the example above (Fig. 6), Peirce demonstrates the functions on an existential graph by diagramming the logical proposition that a human is an animal, an animal is mortal and therefore a human is mortal. For Peirce this logic is mediated through (mental and physical) performances which cut and divide a continuum and register shapes with humans and animals. This is a valuable approach but Peirce's diagrams have limitations and blindspots, which become apparent in contrast with Châtelet's critical diagrammatology-the latter being, as Kenneth Knoespel describes in his introduction to Figuring Space, a "bringing into range of the phenomenological analysis of diagrams and diagrammatic practice in science."28

Châtelet asserts that diagrams are produced through gestures, for a diagram does not make a secure and lasting connection between things-it does not capture relations-and might be better thought of as a "propulsion, which gathers itself up again in an impulse, of a single gesture that strips a structure bare and awakens in us other gestures." ${ }^{29}$ Châtelet, too, understands that diagrams are commonly composed of cut-outs but questions whether it is possible to strip things of their mobility, to cut them out and name them, without leaving a scar? It should not be a surprise that Châtelet finds violence here; after all, Peirce, in naming his diagrammatic gestures as cuts, supplies as good a term as any for defining diagrams.

For Châtelet, the cut-outs of mathematical and abstract figures do not compare well with the life of physical beings, seemingly lacking or dead in comparison. His project, then, is to explore whether physicalmathematical arrangements can be produced which escape the poverty of abstraction. Châtelet suggests that despite Aristotle's blindness on many matters he finds the Greek philosopher's equation of motion with potential helpful. This is because a diagram of motion is less the presentation of a passive state and more a knotting of the 'already' with a 'not-yet'. In this, Châtelet's diagram, as analogue form, can be understood "to inaugurate a family of gestures" that registers virtual or multiple forms, in contrast to rule bound devices (such as
28 Kenneth Knoespel (2000),

"Diagrammatic Writing and the Configuration of Space", in Gilles Châtelet, Figuring Space, ix.

29 Gilles Châtelet, Figuring Space, 9. 
1 camouflage ['kæmofla:3] pattern recognition with flowing borders. Figuring Space, 18-9. algorithms and Pierce's existential graphs) which might only produce a repeatable action and thought. Châtelet offers a number of examples of motion as potential. Firstly, he suggests that when ice melts, this is not a process involving, as he states, "ice that 'can' melt, but of ice that is 'really' in the process of melting, water is of course 'potential' in ice, but above all it actualizes itself there. [...] there is in mass something other [...] than extension." 30 Another way of putting this is that any mass is elastic, an idea Châtelet adopts from Leibniz. Importantly, for Châtelet, while mass is limited in physical reality (as forces are restricted by inertia), in thought and diagrammatic presentation (or a diagrammatic imaginary) mass can be unfolded or compressed without such limits-a diagram condenses without diminishing complexity or potential for 'amplitude'.

It is important then, that Châtelet argues for devices or modes of presentation which allow for multipliciity and change. He describes key scientific diagrams as "allusive devices staging spatial negativity," and advocates for a spatial dialectic pitched against devices focused solely on extension. This spatial dialectic proceeds from Châtelet's reading of Kant and is opposed to the negative dialectics of Hegel. It is a concept that presents the (fittingly diagrammatic) image of a balancing of different states or spaces. This would be an art of producing a figure which points to potential (multiple) states and relations, engendered by a diagram as dialectical balance, which can become unstable through carrying (in thought) more than ample space or many different or multiple states rather than a synthesis of states. In this, a diagram opens out to several dimensions, to which points surge "like taking sides." What Châtelet is suggesting is that diagramming can gesture towards different and contrasting states, relations and dimensions and temper the violence of logical cuts that endeavour to fix the hierarchies of things and their relations. The diagrammatic imaginaries of Peirce and Châtelet can be said to have different destinations related to the degrees of attention paid to either logical and mathematical or virtual and physical relations-they address different paradigms.

If Pierce's diagrams can be said to focus on inferred relations, Châtelet favours scientific figures concerned with actualisation of the virtual. Both approaches are valuable and reveal each other's limits perhaps, but Châtelet's diagrammatic theories are more reflexive, the 
paucity of logical and mathematical cuts is revealed and assuaged through a diagrammatic approach that registers embodiment and potential. Perhaps this is an ethical and aesthetic problem?

It matters what mediations diagram universes. We have only to view NASA's Big Bang Expansion (Fig. 8) to understand how Châtelet's thoughts on the art of figuring space can offer a more dynamic image of a dynamic universe. While NASA's diagram can be said to present the universe as a cut-out floating in a space (an impossible image, for there is nothing beyond or surrounding our universe), the cone is an elastic figure. This corresponds with what Châtelet's approach advocates, the importance for cut-outs to be elastic, and gesture towards multiplicity and different durations and states.

With a concern for elasticity comes an interest in perspectives and horizons, which for Châtelet are more than spatial or boundary markers, they are where science, art and philosophy meet. Once chosen, perspective points and horizons carry everything-they determine everything. In this, Châtelet is referring to a horizon line or point as a spatial device which not only marks a viewpoint (from which other things are understood) but which also produces a vanishing point beyond which nothing can be 'seen' or known (the horizons of singularities posited by astrophysics would be an example).

Although diagrams with vanishing points are limited by spatial clichés (to draw a horizon is to master space), Châtelet asserts that diagrams deprived of horizons function only as a metric count or a numbering of elements, presenting merely trivial relations. That is, such diagrams are reductive and lack the richness of diagrams which take account of space and time and the potentiality of states and relations (and, it can be added, the position of the observer-participant). Again, the target is set theory, but if Châtelet considers a diagram without a horizon capable of only presenting a series of units-a difference without real difference (as illustrated in Fig. 9)-he acknowledges that horizons or vanishing points present a challenge. What use is a horizon if it marks a point in time and space beyond which everything is inaccessible? One might think this a problem. Châtelet thinks otherwise and suggests that a horizon point, rather than being a limit, subverts the finite. It is only the limit of a viewpoint (which is an embodied perspective). In this, a horizon point is a deli- 

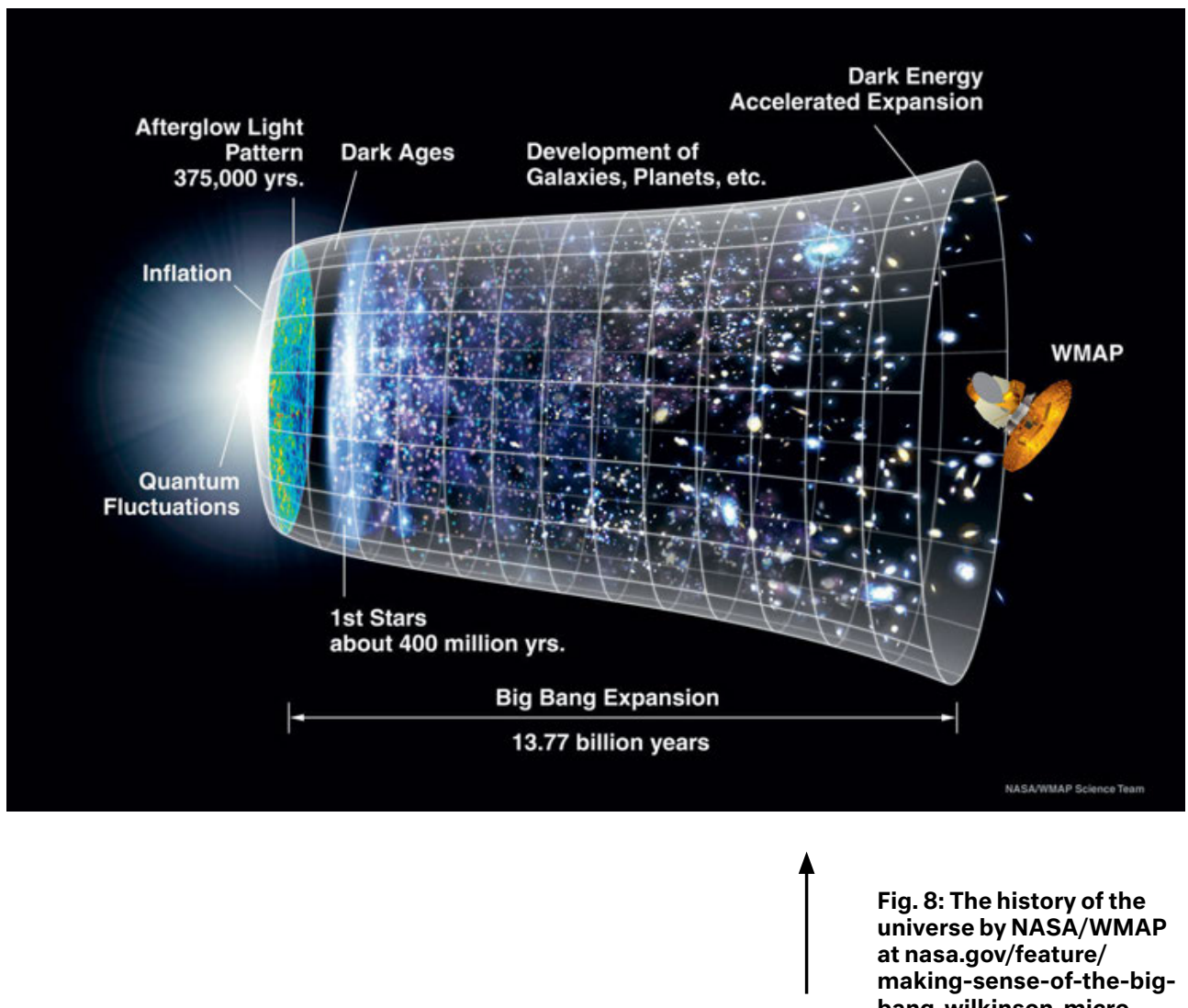

Fig. 8: The history of the universe by NASA/WMAP at nasa.gov/feature/ making-sense-of-the-bigbang-wilkinson-microwave-anisotropy-probe
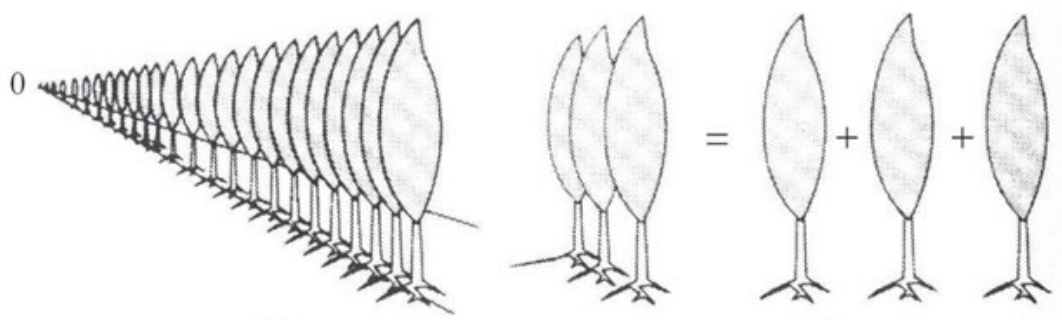

$12 \mathrm{a}$

$12 \mathrm{~b}$ set theory

Figure 12 Poplars

Fig. 9: 'Poplars' by Gilles Châtelet (2000), Figuring Space: Philosophy, Mathematics and Physics, (Dordrecht: Kluwer Academic Publishers), 52. 
cately balanced (and allusive) device, creating a 'pact'

between an image (with limitations) and the forces beyond the horizon which can explode the image into multiple dimensions and perspectives. In this, Châtelet suggests something seemingly impossible, which is to place oneself not in space and time of the image but in the blind spot (the horizon point) of an image through "audacious thought experiments" (a bold fictioning), to explore all possible perspectives and formations. Like Wheeler, Châtelet desires to cross horizons, and he is similarly impressed by Einstein perched on a photon at the horizon of velocity-though the scientist was, Châtelet suggests, still captured by the clichés of mechanics. Following Châtelet's argument never to probe horizons is to have an impoverished outlook and Châtelet advocates for a radical diagrammatic imaginary for the sciences which is at least the equivalent of any science fiction or art practice concerned with the seemingly impossible.

\section{Imaginary time}

In leaving firm ground for horizon points, is Châtelet's diagrammatic, science fictioning wildly unscientific? Some astrophysicists, while insisting on the boundaries of time and space, are not averse to crossing boundaries. In his last book, Stephen Hawking writes of a theory he developed with Jim Hartle, which addresses the problem of producing a unified theory of physics that can address the beginning of our universe. ${ }^{31}$ The problem is well known: classical physics and the theory of relativity engenders an understanding of the relations of gravity, mass and energy in space but this all breaks down at the level of very small measurements or distances (including at the initial

31 Stephen Hawking (2018), Some Brief Answers to The Big Questions, (John Murray: London). stages of the universe following the big bang). Famously, as Wheeler stated, at the quantum level there is uncertainty and all calculations of probability are approximate and not precise. Hawking notes that some scientists are trying to address the problem of a unified theory of physics by combining Einstein's ideas with Richard Feynman's theory proposing that the universe has multiple histories, which is Feynman's response to the uncertainty of events at the quantum level. But this does not help Hawking in his work addressing how the universe came into being. The universe may be approached as having multiple histories, but this does not counter the idea that the

\section{capital ['kæpitl]}

in an all too raw mytho-poetic, capital is not dissimilar to the game of 'hot potato'-except that what is passed from pillar to post, is meant to accumulate 'value' and therewith able to be passed (sold) ever onward, extracting profit in the circulation of exchange. in 1927 russian filmmaker sergei eisenstein planned to make a film based on marx's theory and the notion of capital that should function as a visual instruction in the dialectical method. the film however was never financed. 
32 Stephen Hawking, Some Brief Answers, 55.
33 Lee Smollin (2013), Time Reborn, (London: Penguin Books Ltd), 130-4. beginning of the universe is a single or singular event, which Hawing identifies as "a boundary in time." Feynman's theory does not illuminate this boundary or shed light on what Hawking calls the "boundary conditions" of the universe, which a scientist may need to know to address the early moments of the cosmos. Hawking laments that if we cannot see the boundary conditions from a point beyond that boundary, our perspective on any event is itself limited. But then Hawking suggests something unexpected, crafty even, "[... I]f the frontier of the universe was just at a normal point in space and time, we could go past it and claim the territory beyond as part of the universe." 32 This diagrammatic re-plotting or re-imagining of the big bang as a "normal point" engenders multiple perspectives of the big bang, from points after and before the event, the latter perspective being impossible as there was no space and time before the big bang (which Hawking assures us is the case).

What is of interest here is not whether Hawking's and Hartle's "no-boundary proposal" gets us closer to understanding the big bang. Rather, the focus here is on a diagrammatic imaginary that takes us beyond a limit or boundary point to occupy a blind spot and open up new perspectives that seem in accord with Châtelet's call to explode horizons. Hawking, while acknowledging the contradictions of this performance, recruits the concept of "imaginary time" for this venture, which he notes has nothing to do with "real time"; rather, this imaginary time is a "mathematical trick to make the calculations work." An objection could be raised that Hawking and Hartle engage in mathematical fictions that may add up but cannot be tested empirically.

This is a criticism that some, like physicist Lee Smollin, level at many theories that do not produce verifiable models. ${ }^{33}$ Smollin crusades against a concept shared by many physicists, including Einstein, that time is an illusion, arguing that time and physical laws are natural and evolutionary attributes of our universe and that physics needs to address "the reality of time." In diagramming pre-singularity spaces and times, Hawking's and Hartle's proposal, would seem quite a subversive undermining of the reality of time given the insights this might provide. Here an analogy between the sciences and art is useful. 
Samuel Delany, in Silent Interviews, explains how alternative models of reality, as found in the paraspaces of science fiction, are subversive and transformative. In this, paraspaces can be likened to Châtelet's allusive devices of science:

"[W]e have to note that our paraspaces are not in a hierarchical relation-at least not in a simple and easy hierarchical relation-to the narrative's 'real', or ordinary, space. What goes on in one subverts the other; what goes on in the other subverts the one alternative space is a place where we actually endure, observe, learn, and change-and sometimes die. With these paraspaces the plot is shaped, as it were, to them. And inside them, the language itself undergoes changes [...] is always rotated, is always aspiring toward the lyric." 34

\section{There it is, spelled out}

Displacement, dislocation and transformation are the by-products of marking and surpassing limit points, which is where the diagrammatic imaginaries articulating scientific devices and the paraspaces of science fiction converge. The value of this for both practices are the same: perspectives can be revolved, expanded, extended and interchanged and blind spots can be illuminated. It may be that the sciences keep one foot firmly on solid ground and go further in their forays across horizons. However, artists more often than scientists may knowingly present darkened and distorted imaginaries that reflect or produce an awareness of the gaze of the observerparticipant (Delany offers the image of science fiction as 'mirrorshades'). ${ }^{35}$ The significance of this, particularly in relation to an increasing proliferation of digital imagery and numerical modelisa-

tions, seems important for recognising desires for mastery, highresolution capture and the colonising of space. This chapter concludes with a discussion of this problem, which addresses whether (diagrammatically speaking) perspective has a future or not?

\section{Flatlands, multiverses and scientific-hollywood diagrammatic imaginaries}

In addressing astrophysicist's use of digital media, it is productive here to return to Latour's writing on the sciences and his ideas concerning tools that function as "intermediaries," as vehicles that 
Bruno Latour, We Have Never Been Modern, 77-8.

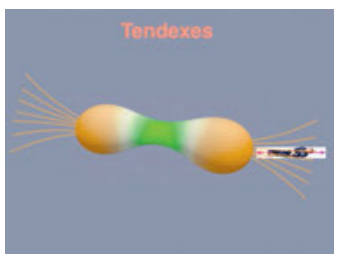

$$
4
$$

Fig. 10: Still from an animation of two black holes colliding by Kip S Thorne and SXS Collaboration
37 Kip Thorne (2012), Interview at space.com/17086bizarre-blackholes-kip-thorneinterview.html convey information, and those he views as "mediators." In naming a device as a mediator, Latour identifies a process which "creates what it translates as well as the entities between which it plays the mediating roles." ${ }^{36}$ It is important then to differentiate between intermediaries and mediators. An example belonging to the group of devices Latour names intermediaries is the Laser Interferometer Gravity Wave Observatory (LIGO), which registers colliding black holes and indexes gravity waves through an arrangement of mirrors and lasers (which would surely have interested Smithson). To process and present information gathered by LIGO, scientists use animated, digitised diagrams or numerical models, which are examples of mediators, which translate information into moving icons of intelligible relations. The intention here is not to question the veracity of numerical models but to ask how, if at all, they mark perspectives and horizons. A related question is whether digital modelisations register, in any way, the perspective of the observer participant (like a reflection in mirrorglasses) but reflection fades when a screen, presenting a digital model, would seem to be its own world. This is not the protestations of Luddite. It is an exploration of the difference mediators can make. It should be acknowledged that for astrophysicist Kip Thorne, numerical modelisations-computer programmes producing simulations-count as one of the most important developments for astrophysics in recent years. The diagrammatic animation of two black holes colliding (Fig. 10), the event which a LIGO registers, is an example of a simulation Thorne uses in lectures about his work. ${ }^{37}$ Thorne's computer simulated singularities differ from Wheeler's image of a black hole without hair in significant ways. It is not just that Thorne's animation lacks the humour or lyricism of Wheeler's diagrammatic imagery. In Throne's simulation, collapsing stars are given a positive presence or shape, the singularities are not exactly black holes (for the obvious reason of producing lessons concerning the cosmos). Thorne's simulation looks like an animated, cosmic existential graph, which Pierce might have been proud off, though there is no denying that in this presentation of singularity collision, collapsing stars are created as elastic. It would be nostalgic to worry over the demise of the lyrical or analogue graph. 
And surely, Thorne and his colleagues have an understanding of singularities that can only be gained from computer simulations. It is important to recognise too that Thorne is a theoretical physicist who suggests, in public lectures, that the viewpoint which gazes upon his animated figures is from a higher bulk brane dimension-the hyperspace which some theoretical physicists suggest our universe is moving through.

This is a compelling idea. In his popular book, The Science of Interstellar, Thorne explains this concept through reference to a famous fiction, Flatland by Edwin Abbott, about a two-dimensional world visited by a three-dimensional being from Spaceland. ${ }^{38}$

The protagonist of the novel, a square, cannot see the bulk of the three-dimensional sphere, only a slice of the being is visible as it passes through the square's two-dimensional universe. But after being lifted up by the sphere and seeing his two-dimensional world from the perspective of Spaceland, the square reasons that there could be many more dimensions than three. In relation to the example of Flatland, Thorne asks:

"Suppose that our universe, with its three space and one time dimensions, really does live in a five-dimensional bulk (four space and one time). And suppose there are 'hyperspherical beings' who live in the bulk [...]. The bulk being's surface would have three dimensions and its interior would have four. Suppose that this hyperspherical bulk being, traveling in the bulk's out direction or back direction, were to pass through our brane. What would we see? The obvious guess is correct. We would see spherical cross-sections of the hypersphere." 39 A question follows: what does the hyperspherical being see of our world. Answer: everything, without limits, just like the sphere's view of Flatland. Does this mean Thorne's hyperspace beings have no blind spots, which is a question concerning an imaginary and unbridled agency with mastery over nature (which perhaps tempts all sciences)? It is perhaps hard to see what is at stake here.

This question can be turned on its head if we return to Châtelet's figuring space and ask again: what is lacking in a diagrammatics without perspectives or negative space? If we address the importance of these formal and embodied aspects of images for modern and contemporary art (also transformed in some practices by digital media) we find examples that may help us understand the challenge
38 Kip Thorne (2014), The Science of Interstellar, (New York: W.W. Norton \& Co). Cf Edward Abbott (1992 [1884]), Flatland: A Romance of Many Dimensions, (New York: Dover Thrift).

39 Thorne, The Science of Interstellar, 9-10.
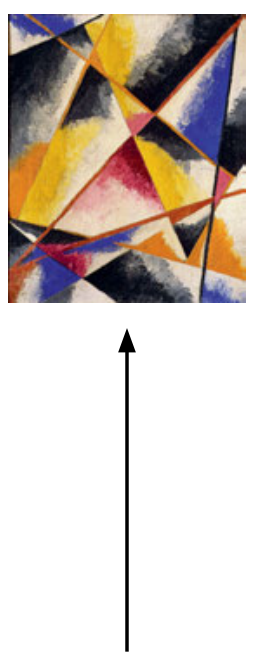

Fig. 11: Untitled, Lyubov Popova 1916

care [keə]

giving a damn, or two. 
40 Cf moma.org/ artists/4694
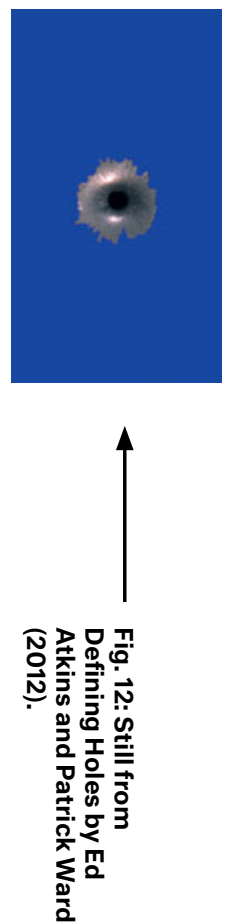

41 Ed Atkins and Patrick Ward (2012), Defining Holes, (Ljubliana: Mestna Galerija). presented by new digital-hyperspace hybrids, only from the paradigm of aesthetics. The term 'negative space' in art relates to abstract shapes made when drawing positive figures in a composition. These negative shapes (gaps, holes, voids) are said to exist between positive shapes which in flat, drawn and painted images can easily be inverted (in the act of looking and in the mind) to become positives, creating ambiguity and a multiplicity of forms. In this act, the agency of the observer and role of media becomes apparent (to the observer). Perhaps the best example of such an approach is found in the architectonic works of Lyubov Popova (1889-1924).40 Her abstract paintings present shapes which appear as both solids and voids, their relation fixed only (in the mind) at the point of registration, like particles in quantum superposition theory (Fig. 11).

Over a hundred years have passed since Popova's negative spatial dialectics enabled viewers of paintings to realize they are observers and participants but an interest in voids, negative spaces and reflexivity can be found in the digital presentations of artists working today, an example being Defining Holes (2012) by Ed Atkins and Patrick Ward, which comprises of a number of analogue clips and digital simulations of holes, gaps and spaces (Fig. 12). But for Atkins and Ward, it seems that the digital elides indexicality or perspective, and presents a very different kind of negative space. To accompany the screening of the film, the artists issued a joint statement which could be read as a warning to all who produce digital simulations:

"A hole is a parasite from the void [...] negatively charged paradoxes whose nominal existence disguises an essential un-being [...] Within the (analogue) moving image, holes define the presence of the medium. Those dividing lines that lie abyssal between every discrete frame [... are] traversed via an illusionary bridge: the persistence of vision. This impression of movement is an analgesic of ideological potential [...] Digital video is something else. The appearance of movement is no longer predicated on the recurrence of absence (digital video is not indexical) [...] there is no movement because there is no matter. The digital is entirely hole, bordered and defined by its own dreamed-of, vacated representations. ${ }^{41}$ 
This cryptic statement needs unpacking: analogue presentations are indexical. In Atkins and Ward's example a hole is captured by celluloid film with its sprocket holes and horizontal bars dividing each frame; a presentation of moving frames faster than they eye can sense, engendering the projection of an absent hole, creating an illusion of presence and movement or space and time. The moving image of a hole that is digitally rendered or simulated may have frames of a kind, but a hole presented in digital animation or film has never physically existed and, therefore, there is nothing indexed or absent in this presentation. Atkins and Ward suggest digital video is itself a hole in which matter is not present, even as indexical trace, the implication being that the digital can create semblances without substance. What to make of Atkins and Wards statement? Despite the negative overtones of their commentary, the most productive approach is perhaps to acknowledge the advent of the digital marks a departure for image-making practices and for diagrammatic imaginaries. Combining the representational power of digital or numerical modelisation with an imaginary diagrammatics of hyperspace is a new challenge-the potential of a digital hole in which a universe can be simulated.

It would be a strange discussion of the diagrammatic imaginary that rejected diagrams and models for appearing to much like vivid dreams. And it would be a little ridiculous to suggest Kip Thorne and other scientists mistake digital images for real things-they no doubt know the difference (and what the 'real thing' is when addressing mathematical simulations might be a more complex question than it would first seem). Something nags here though. There still seems to be a blind spot. Thorne's hyperspace-beings live in a paraspace that subverts models of reality that engage with limit points in time and space-for hyperspace beings see all without limit through an inhuman, disembodied gaze-but this new hyperspace subject is produced through an art of creating semblances that sneaks a human perspective into the bulk brane dimension: a kind of Hollywood effect. Thorne famously contributed to the film Interstellar (2014) as a consultant, and the scientist expressed his excitement that his calculations were used to make digital animations of black holes for the film: "For me, those film clips are like experimental data: they reveal things I never could have figured out on my own." 42

42 Thorne, The Science of Interstellar, 98. 
Thorne's contribution to the film was significant, not least in his speculations and computations concerning the fifth dimension, a concept necessary for the film's narrative development and star (non-human) actor, the tesseract. This device, which in the film's narrative is made by humans in the future, is a five-dimensional object which allows a human (a character called Cooper) to see across time and space. It is the tesseract which allows a father to send messages across space and time to his daughter. The science of Interstellar is correct (Thorne made sure of this), even if the film is overlaid with questionable moral and romantic themes. The tesseract, which is digitally constructed for the film, can be seen in some sense as a paraspace that answers Châtelet's call to explode horizons and vanishing points, though the results might be unexpected. It is a paraspace that engenders an omnipotent gaze that surpasses embodied perspective.

What is marked here? In the logics of a diagrammatic imaginary of hyperspace, there a trade-off between know-how and knowing and a time for reflection. But then the idea that time-the time of reflection, critical or otherwise-is necessary for understanding the universe is not an idea held by everyone. After all, as discussed above, for many astrophysicists, time is an illusion.

\footnotetext{
cephalopod ['sefələ,pad]

literally meaning 'head-feet' with their deeply mesmerising horizontal pupil-eye

intelligently taking in their surroundings in one fell swoop. our evolutionary distant (very distant) cousin, has a wisdom-like curiosity that extends into each of its eight armpit-genital-leg-suckered knowledge spheres. on average a 2 year life-span (even for the largest of them). one has to wonder whether in their unfathomable intelligence and the pace at which they learn, that, like their alien human cousin, one million years+ removed, they somehow know that at some point they will die.
} 